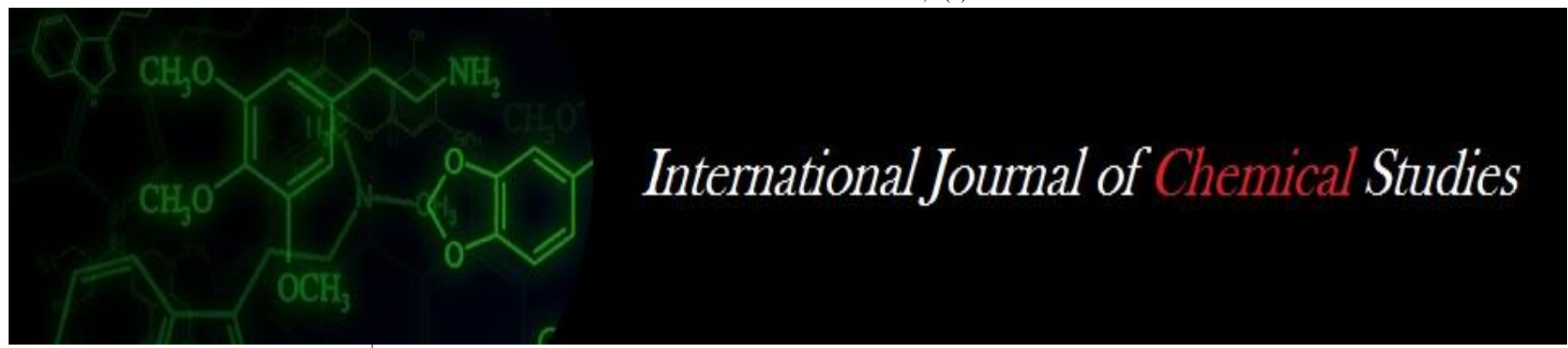

P-ISSN: 2349-8528

E-ISSN: 2321-4902

www.chemijournal.com

IJCS 2020; 8(2): 800-802

(C) 2020 IJCS

Received: 16-01-2020

Accepted: 20-02-2020

\section{Ummay Hafsa}

Department of GPBR,

Agricultural College, BAU,

Bihar, Sabour, India

\section{SP Singh}

Department of GPBR,

Agricultural College, BAU,

Bihar, Sabour, India

Sweta Sinha

Department of GPBR,

Agricultural College, BAU,

Bihar, Sabour, India
Corresponding Author:

Ummay Hafsa

Department of GPBR,

Agricultural College, BAU,

Bihar, Sabour, India

\section{Genetic divergence study in rice (Oryza sativa L.) Using cluster analysis and principal component analysis}

\author{
Ummay Hafsa, SP Singh and Sweta Sinha
}

DOI: https://doi.org/10.22271/chemi.2020.v8.i21.8863

\begin{abstract}
The study was undertaken to assess the genetic diversity among the non-parental type rice genotypes using hierarchical cluster analysis. Cluster analysis, based on all the studied traits, divided the genotypes into 3 clusters. Among the 3 clusters, cluster III consisted of maximum number of genotypes (19) followed by cluster II (11) and cluster I (11). A comparison of the mean values of three clusters for 9 characters revealed considerable differences in cluster mean values for all the characters studied. The present study revealed that cluster I had highest mean values for grain yield ( 1.903), flag leaf length (1.397) and panicle length(1.349) and lowest mean values for flag leaf width $(-0.385)$ and days to flowering (-1.959). Cluster II had highest mean values for days to flowering (0.109) and 1000 grain weight (0.074) and lowest mean values for characters like tiller number(-0.392) and grain yield (-0.314). Cluster III showed highest mean values for characters like flag leaf width (3.597) and tiller number(1.911) and lowest mean values for characters like flag leaf length (-0.674) and days to flowering $(-0.375)$. None of the clusters contained genotypes with all the desirable traits which could be directly selected and utilized. The relationship between different genotype of different cluster is important for further breeding programme.
\end{abstract}

Keywords: Genetic divergence, Oryza sativa L. component analysis

\section{Introduction}

Rice is considered as one of the most important crops of India. It has a socio-economic importance in our lives due to the fact that in many Asian countries it's used in sacred rituals. It has indubitably become a part of Asians souls and its importance is irreplaceable by any other grain. Rice is usually grown in rainfed and lowland areas due to which its production is continually threatened by series of biotic and abiotic stress. Even though rice is being cultivated under flooded and irrigated condition, most of the rice varieties under cultivation are susceptible to flooding if the plants are submerged under water for more than seven days (Adkins et al., 1990) ${ }^{[1]}$. Hence, developing submergence/flood tolerant rice genotypes will be useful in reducing yield loss in rice in these areas.

The principal component analysis is a multivariate statistical technique for identifying and simplifying complex data sets. The ability of this procedure is to transform a number of possibly correlated variables in to a smaller number of variables called principal components (Everitt and Dunn 1992). Each principal component is a linear combination of the original variables.

\section{Materials and Methods}

The present investigation was carried out in the Research Farm of Bihar Agricultural University Sabour, Bhagalpur, Bihar, which is geographically situated between $25^{\circ} 15^{\prime} 40^{\prime \prime}$ ' N latitude to $87^{\circ} 2$ ' $42^{\prime}$ ' E longitude at $46 \mathrm{~m}$ above mean sea level. All types of facilities necessary for cultivation of successful crop including field preparation, inputs, irrigation facilities and labours were provided by Rice Section, Department of Plant Breeding and Genetics, BAU, Sabour. Weather condition during entire cropping season was normal with good monsoon during June to November. Temperature was recorded at 7:00 AM for minimum and at 2.00 PM for maximum temperature of the day. The experiment was carried out in an non-replicated trail as it was segregating material. 
Each row consisted of 15 plants with spacing of $20 \times 15 \mathrm{~cm}$ inter and intra row spacing. A total of 186 F2 segregants were considered and out of which 49 plants were recombinant (Swarna sub 1) types. The phenotypic (morphological) observations for these 49 F2 segregants was carried for the following nine characters which includes days to flowering, plant height, panicle length, flag leaf length, flag leaf width, number of tillers, grain per panicle, 1000 grain weight and grain yield/plant.

\section{Results}

\section{Clustering pattern}

Hierarchical cluster analysis was performed. It is represented on a dendrogram. The diagram shows the relationship among different individuals.

Cluster analysis, based on all the studied traits, divided the genotypes into 3 clusters. Among the 3 clusters, cluster III consisted of maximum number of genotypes (19) followed by cluster II (11) and cluster I (11).

\section{Cluster mean}

A comparison of the mean values of three clusters for nine characters has been presented in Table no 1. Considerable differences in cluster mean values were evident for all the characters studied.

The present study revealed that cluster I had highest mean values for grain yield ( 1.903), flag leaf length (1.397) and panicle length(1.349) and lowest mean values for flag leaf width (-0.385) and days to flowering (-1.959).

Cluster II had highest mean values for days to flowering (0.109) and 1000 grain weight (0.074) and lowest mean values for characters like tiller number(-0.392) and grain yield $(-0.314)$.

Cluster III showed highest mean values for characters like flag leaf width (3.597) and tiller number(1.911) and lowest mean values for characters like flag leaf length $(-0.674)$ and days to flowering $(-0.375)$.

None of the clusters contained genotypes with all the desirable traits which could be directly selected and utilized.

Table 1: Characteristic means of three cluster groups of $F_{2}$ segregants (Swarna Sub1 type)

\begin{tabular}{|c|c|c|c|}
\hline & $\mathbf{1}$ & $\mathbf{2}$ & $\mathbf{3}$ \\
\hline PH & 1.002 & -0.109 & 0.405 \\
\hline PL & 1.349 & -0.022 & -0.225 \\
\hline FL & 1.397 & -0.076 & -0.674 \\
\hline FW & -0.385 & -0.283 & 3.597 \\
\hline TL & 0.867 & -0.392 & 1.911 \\
\hline NG & 1.272 & -0.042 & 1.592 \\
\hline TW & 0.010 & 0.074 & -0.292 \\
\hline GY & 1.903 & -0.314 & 2.960 \\
\hline DF & -1.959 & 0.109 & -0.375 \\
\hline
\end{tabular}

$\mathrm{DF}=$ Days to flowering, $\mathrm{PH}=$ Plant height $(\mathrm{cm}), \mathrm{PL}=$ Panicle length $(\mathrm{cm}), \quad \mathrm{FL}=$ Flag leaf length $(\mathrm{cm}), \quad \mathrm{FW}=$ Flag leaf width $(\mathrm{cm})$, $\mathrm{TN}=$ Number of tillers, GPP= Number of grains/panicle, $\mathrm{TW}=1000$ grain weight.

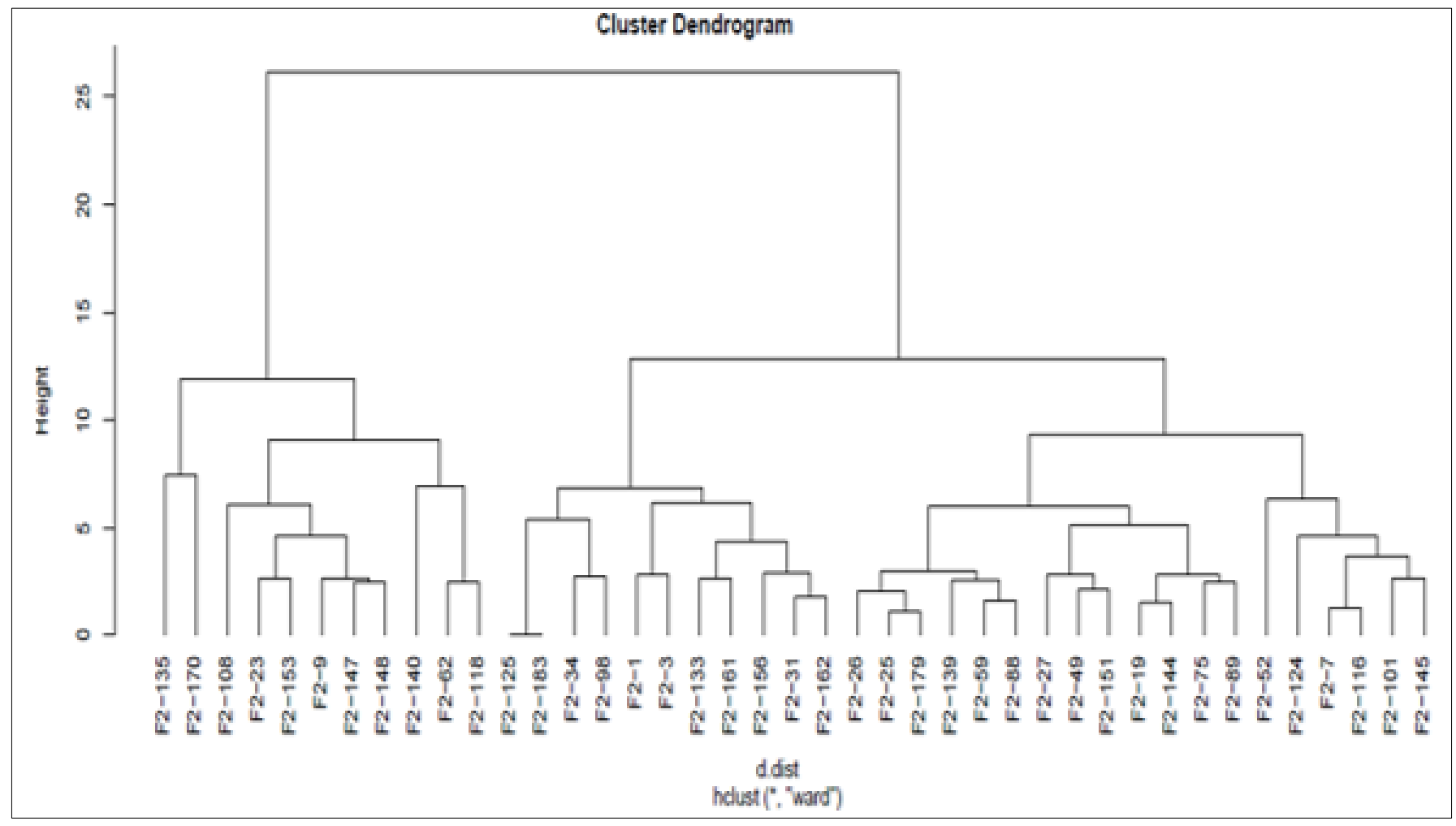

Fig 1: Dendrogram of F2 segregants (Swarna Sub1 type) based on nine quantitative traits

\section{Principal component analysis}

Table 2: Principal components analysis showing the contribution of 9 quantitative traits towards divergence among the $F_{2}$ segregants $($ Swarna Sub1 type)

\begin{tabular}{|c|c|c|c|}
\hline & PC1 & PC2 & PC3 \\
\hline Days to flowering & -0.612 & 0.225 & 0.431 \\
\hline Plant height & 0.740 & -0.325 & -0.065 \\
\hline Panicle length & 0.652 & -0.453 & 0.104 \\
\hline Flag leaf length & 0.444 & -0.474 & 0.067 \\
\hline
\end{tabular}




\begin{tabular}{|c|c|c|c|}
\hline Flag leaf width & 0.261 & 0.729 & -0.182 \\
\hline No. of tillers & 0.614 & 0.464 & 0.388 \\
\hline Grains per panicle & 0.731 & 0.166 & -0.267 \\
\hline 1000-seed weight & -0.036 & -0.213 & 0.731 \\
\hline Grain yield/plant & 0.778 & 0.360 & 0.317 \\
\hline Eigen values & 3.130 & 1.536 & 1.096 \\
\hline \% of Variance & 34.779 & 17.063 & 12.175 \\
\hline Cumulative \% & 34.779 & 51.842 & 64.016 \\
\hline
\end{tabular}

$\mathrm{DF}=$ Days to flowering, $\mathrm{PH}=$ Plant height $(\mathrm{cm}), \mathrm{PL}=$ Panicle length $(\mathrm{cm}), \mathrm{FL}=$ Flag leaf length $(\mathrm{cm}), \mathrm{FW}=\mathrm{Flag}$ leaf width $(\mathrm{cm}), \mathrm{TN}=$ Number of tillers, $\mathrm{GPP}=$ Number of grains/panicle, $\mathrm{TW}=1000$ grain weight.

Table 2 represents the principal component and percentage contribution of each component to the total variation. The first principal component accounted for $34.779 \%$ of the total variation in the population. In PC1 grain yield/plant contributed most to the variation $(0.778)$, followed by plant height (0.740). 1000 seed weight and days to flowering contributed negatively to the first component.

Second principal component contributed $17.063 \%$ of the total variation. Characters that contributed to the second principal component include flag leaf width (0.729) having the maximum value followed by number of tillers (0.464) and grain yield per plant (0.360).

The third principal component accounted for $12.175 \%$ of the total variation in the population. In PC3 1000 seed weight (0.731) contributed most to the variation, followed by days to flowering (0.431).

\section{Discussion and conclusion}

Hierarchical cluster analysis (HCA) shows the average linkage between the genotypes through a dendrogram. Clustering of genotypes based on mean of similar characters has also been proved by Elyasi et al. (2014) ${ }^{[3]}$, Tejaswini et al. (2016) ${ }^{[6]}$ and Ahmed et al. (2016) ${ }^{[2]}$. The PCA yielded three principal components explaining a total of $64.016 \%$ of the variance for the entire set of characters. Principal component analysis revealed the Eigen value greater than unity for all the components. It would be helpful in proving that the high level of genetic variation exists and explains which character contributes most towards divergence. Principal component analysis has been used in rice by Sathish et al. (2017) [5] and Ojha et al (2017) ${ }^{[4]}$. Preforming the Hierarchical cluster analysis (HCA) and Principal component analysis suggests that among the nine morphological characters the plants which possess the character grain yield/ per plant can be considered to be the most important and beneficial for further crop improvement.

\section{References}

1. Adkins SW, Shiraishi T, Mc Comb JA. Submergence tolerance of rice-A new glasshouse method for the experimental submergence of plants. Physiologia Plantarum. 1990; 80:642-646.

2. Ahmed F, Rafii Y, Ismail R, Juraimi AS, Rahim HA, Latif A et al. The addition of submergence-tolerant Sub1 gene into high yielding MR219 rice variety and analysis of its $\mathrm{BC} 2 \mathrm{~F} 3$ population in terms of yield and yield contributing characters to select advance lines as a variety. Biotechnology and Biotechnological Equipment. 2016; 30(5):853863.

3. Elaysi S, Abdollahi Shapour, Mollasadeghi Vahid. Cluster analysis of 24 Genotypes of Modified rice According to Qualitative and Quantitative traits, Bulletin of Environment, Pharmacology and Life Sciences Life Science. 2014; 3(8):109-111.
4. Ojha GC, Sarawgi AK, Sharma B, Parikh M. Principal component analysis of morpho-physiological traits in rice germplasm accessions (Oryza sativa L.) under rainfed condition. International Journal of Computer Systems. 2017; 5(5):1875-1878.

5. Sathish V. Senapati B Principal Component Analysis of Morphological and Yield Attributing Traits In Advanced Breeding Lines of Rice Grown at Rainfed Shallow Lowland Condition of West Bengal.

6. Tejaswini KLY, Manukonda S, Ramana RPV, Kumar R, Raju LA, Krishna MS. Cluster analysis studies in rice (Oryza sativa L.) using wards minimum variance method Journal of Agricultural and Crop Research. 2016; 4(9):129-139. 